\title{
Pengembangan Manajemen Pemasaran Pada Klinik Bisnis Tebing Tinggi
}

\author{
Muhammad Umar Maya Putra ${ }^{1}$, Windy Aginta ${ }^{1}$ \\ Universitas Al Azhar \\ Jl. Pintu Air IV No. 214, Kwala Bekala, Medan, Sumatera Utara, (061) 8366679 \\ umar_yazli@yahoo.com
}

\begin{abstract}
This paper starts from the concept of Tebing Tinggi Clinic which seeks to develop the marketing concept by strengthening the technology base. This paper tells the training model to MSMEs to know the importance of the role of marketing in improving business development. The method to be used is experimental learning from experience and the concept of literature study on marketing management science. Submission in the form of lectures, focus group discussions that they can actively participate in this activity. In this training material was presented: marketing management program. After the activity was carried out, it was found that MSMEs were very enthusiastic in following it, evidently that MSMEs actively asked and tried to develop business with technology marketing in undergoing MEA. This is an ongoing agenda to prepare MSMEs for more competitiveness in Tebing Tinggi City.
\end{abstract}

Keywords: Clinic, Business, Management, Marketing

Abstrak-Tulisan ini berawal dari konsep Klinik Tebing Tinggi yang berupaya mengembangkan konsep pemasaran dengan memperkuat basis teknologi. Tulisan ini menceritakan model pelatihan kepada UMKM untuk mengetahui pentingnya peran pemasaran dalam meningkatkan pengembangan bisnis. Metode yang akan digunakan adalah pembelajaran eksperimental dari pengalaman dan konsep studi literatur tentang keilmuan manajemen pemasaran. Penyampaian dalam bentuk ceramah, diskusi kelompok fokus bahwa mereka dapat berpartisipasi aktif dalam kegiatan ini. Dalam pelatihan ini disajikan materi: program manajemen pemasaran. Setelah kegiatan dilakukan, ditemukan bahwa UMKM sangat antusias dalam mengikutinya, terbukti bahwa UMKM aktif bertanya dan berupaya untuk mengembangkan bisnis dengan pemasaran secara teknologi dalam menjalani MEA. Hal Ini merupakan agenda yang berkelanjutan untuk mempersiapkan UMKM semakin berdaya saing di Kota Tebing Tinggi.

Kata kunci: Klinik, Bisnis, Manajemen, Pemasaran

\section{PENDAHULUAN}

Jika kita membahas UMKM, masalah yang sering dihadapi adalah pemasaran yang mengenai What dan How untuk bisa terjual sehingga bisa menaikkan omset. Pemberdayaan usaha mikro, kecil dan menengah (UMKM) merupakan langkah yang strategis dalam meningkatkan dan memperkuat dasar kehidupan perekonomian, khususnya melalui penyediaan lapangan kerja dan mengurangi kesenjangan dan tingkat kemiskinan. Implementasi dari pemetaan sosial ekonomi berupa tanggung jawab sosial perusahaan kepada para pemangku kepentingan dan masyarakat, khususnya di lingkungan masyarakat. Ukuran keberhasilan program pemetaan sosial ekonomi dalam program pemberdayaan yang mempromosikan nilai-nilai moral dengan memperhatikan kebutuhan masyarakat 
pada aspek sosial ekonomi masyarakat secara berkelanjutan khususnya pengembangan dari basis kewirausahaan [1]. UMKM telah menjadi pilar utama penggerak perekonomian Indonesia. UMKM telah memberikan kontribusi yang sangat besar dari segi jumlah usaha dan penyerapan tenaga kerja. Berdasarkan data dari Kementerian Koperasi dan Usaha Kecil dan Menengah, pada tahun 2011, jumlah unit usaha UMKM mencapai 99,98 \% terhadap total unit usaha di Indonesia. Sementara jumlah tenaga kerja yang terlibat mencapai 91,8 juta orang atau 97,3\% terhadap seluruh tenaga kerja Indonesia. Peran konsultan kewirausahaan sangat diperlukan untuk meningkatkan kualitas dari wirausaha pada saat mengalami permasalahan dari proses bisnis. Sebagai pengabdian kepada masyarakat, Para konsultan kewirausahaan akan menghadapi masalah yang akan dihadapi pengusaha untuk menjadi wirausaha mandiri. Para pengusaha mencoba membuat usaha kecil yang akan mendapatkan keterbatasan dalam modal, rencana bisnis dan lokasi yang dapat dipecahkan dengan membuat program pelatihan yang terorganisir [2].

Sumber daya manusia memiliki efek positif untuk kinerja perusahaan dalam menila kelayakan perusahaan sehingga dapat dipahami secara jelas. Modal manusia yang merupakan poin utama dalam meningkatkan kualitas UMKM dituntut adanya dukungan pendidikan kewirausahaan untuk dapat meningkatkan inovasi sehingga dapat meningkatkan kinerja perusahaan [3]. Meningkatkan kesejahteraan sosial merupakan upaya yang sering dilakukan di Indonesia. Kegiatan ini dilakukan baik individu, kelompok, komunitas, media massa untuk pendidikan (beasiswa), kesehatan, distribusi makanan, korban bencana, bantuan untuk melahirkan anak, konflik sosial dan keresahan sosial. Namun, jumlah sumbangan yang diberikan tidak mencukupi, jika dibandingkan dengan sejumlah besar orang yang membutuhkan bantuan khususnya dalam pengembangan kewirausahaan [4]. Mentalitas dan budaya bisnis yang baik memiliki kemampuan untuk memberdayakan siswa untuk membuat hasil yang lebih baik dalam menciptakan produk di masyarakat dan dapat menyerap bidang pekerjaan untuk mengurangi pengangguran. Komunitas lokal akan dihadirkan dengan produkproduk inovatif yang dapat terus tumbuh dari tahun ke tahun [5].

Dalam pengembangan suatu perusahaan, tujuan yang paling diperlukan adalah menghasilkan keuntungan dengan keyakinan untuk meningkatkan meningkatkan kesejahteraan bersama. Kondisi perusahaan terkait dengan aktivitas actor di sekitar perusahaan. Kegiatan ini mempengaruhi kepedulian terhadap perusahaan dan perlu bertindak untuk menciptakan suasana yang harmonis dalam menciptakan pembangunan berkelanjutan [6]. Seiring dengan berkembangnya UMKM sebagai wirausaha mandiri, permintaan manusia selalu mengalami pertentangan dengan maraknya penawaran yang diberikan sektor riil yang bergantung kepada kecerdasan untuk menciptakan strategi produksi, pemasaran dan mental yang kuat serta pengusaha mandiri (presentasi diri) [7]. Pengembangan diri melalui konsep sosial ekonomi, sangat lazim dipergunakan oleh semua pengambil keputusan untuk memetakan suatu kelompok masyarakat. Masyarakat harus dibuat sebagai suatu subjek dalam pembangunan, agar dapat menjadikan suatu konsep pemberdayaan yang aktif sehingga dapat menghasilkan output yang dapat meningkatkan perkembangan suatu perekonomian. Keputusan 
yang diambil juga harus memenuhi suatu keputusan yang terprogram sehingga mampu menjadi suatu landasan keputusan yang dapat diambil suatu proses keputusan yang berkelanjutan [8]. Dengan semangat perubahan dan peran lembaga yang relevan, wajah lanskap lokal di suatu daerah dapat ditingkatkan kualitas sosial ekonomi yang dapat meningkatkan ekonomi suatu daerah. Dengan informasi yang diperoleh secara terprogram, bahwa beberapa hal untuk pemetaan sosial ekonomi telah diprogram dengan struktur masyarakat [9]. Kelayakan proyek ialah hasil dari evaluasi proyek dengan menggunakan beberapa aspek yang akan menentukan apakah proyek yang akan dijalankan dapat dikatakan layak atau tidak layak [10]. Perkembangan ekonomi yang berkembang pesat saat ini, membuat banyak perusahaan baik yang bergerak dibidang jasa maupun produksi serta perdagangan berlomba-lomba untuk memperoleh keuntungan yang lebih baik guna keberlangsungan usahanya di periode yang akan datang. Selain untuk memperoleh keuntungan yang baik, perusahaan tersebut juga berusaha agar kinerja usahanya menjadi lebih baik agar banyak investor yang menanamkan modalnya pada perusahaan tersebut [11]. Sejalan dengan fenomena, data dan fakta yang terjadi, penulis tertarik untuk mengambil judul penelitian yaitu Pengembangan Manajemen Pemasaran Pada Klinik Bisnis Tebing Tinggi.

\section{METODOLOGI PENELITIAN}

Metode yang akan digunakan adalah metode pembelajaran eksperimental di pelatihan keilmuan manajemen pemasaran pada UMKM binaan Klinik Bisnis Tebing Tinggi. Penyampaian berupa ceramah, diskusi kelompok dengan materi Konsep pemasaran dengan berbagai sudut pandang oleh Tim Fakultas Ekonomi dan Bisnis FEB USU dan Entrepreneurship Development Program (EDP) yang dilaksanakan pada tahun 2015. Sumber data dalam penelitian ini adalah dari jurnal internasional, buku, Biro Pusat Statistik yang ditransfer ke dalam diskusi kelompok terarah dengan para peserta.

\section{HASIL DAN PEMBAHASAN}

Model pembelajaran eksperimental di pelatihan keilmuan manajemen pemasaran pada UMKM binaan Klinik Bisnis Tebing dibawakan secara berturut turut oleh tim Fakultas Ekonomi Universitas Sumatera Utara mulai dari Manajer Klibi, Bpk. Wahyu Ario Pratomo dan Bpk. Fahmi Natigor Nasution dan Motivasi bisnis oleh Praktisi Bisnis Bpk. Chairuddin Nasution dan Bpk. Ahmad Rafiki.

Implementasi dari pemetaan sosial ekonomi berupa tanggung jawab sosial dari akademisi untuk mengembangkan potensi di lingkungan masyarakat. Para konsultan kewirausahaan akan menghadapi masalah yang akan dihadapi pengusaha untuk menjadi wirausaha mandiri dan menilai kelayakan UMKM, Fakultas Ekonomi dan Bisnis Universitas Sumatera Utara memberikan session penerapan konsep keilmuan manajemen pemasaran pada Klinik Bisnis Tebing Tinggi sesuai dengan ide dari [1], [2], [3].

Diawali oleh Ketua Departemen Ekonomi Pembangunan Fakultas Ekonomi dan Bisnis Universitas Sumatera Utara dan sekaligus Manager Klibi Tebing Tinggi, Bpk Wahyu Ario Pratomo memberikan beberapa materi motivasi usaha yaitu untuk berkembangnya suatu usaha, PKBL (Program Kemitraan Bina Lingkungan) 
mempunyai banyak sejarah. Tahun 1994, beliau pernah menjadi konsultan PKBL dan pernah mendatangi usaha kerupuk yaitu 1. Kerupuk Biasa, 2. Kerupuk Jangek, 3. Tahu, 4. Kue. Dari usaha yang tersebut sesuai dengan makna dari PKBL seharusnya digunakan untuk membeli barang yang produktif seperti kompor, membuat kue. Namun ada yang menggunakan dana PKBL untuk membiayai kuliah anaknya yang saat itu sudah deadline. Syukurnya usaha tetap lancar dan bisa digunakan untuk pengembangan usaha. PKBL harus berjalan dengan baik dikarenakan setiap kegiatan yang diberikan dana PKBL harus dipertanggung jawabkan dengan baik. Masalah yang sering menghinggapi UMKM adalah bahwa PKBL termasuk laporan bukan sumbangan dan perlu dihimpun informasi secara jelas kepada semua mitra binaan sehingga tidak mengalami kesulitan di kemudian hari. Perkembangan Kota Tebing Tinggi yang akan dibangun jalan tol, Klibi berharap untuk bisa menyewa beberapa tempat didekat jembatan Tol untuk bisa nantinya dijual segala sesuatu hasil olahan yang terbaik. Ini merupakan konsep kedepan perkembangan dari Klibi Tebing Tinggi di masa depan.

Lebih lanjut Untuk Badan Pengawas Obat dan Makanan (BPOM), perlu juga dibahas mengenai penjaminan halal dengan survey syariah islam. Setelah pengawasan pemberian sertifikat, maka setelah habis masanya akan dibuat izin terbaru. Jadi Kita perlu melihat bagaimana label halal dibuat dan dijamin, khusus untuk Klibi Tebing Tinggi untuk label halal bisa dibuat label halal dan yang sebagai proses olahan secara hiegenis. Klibi dalam perkembangannya akan mengembangkan jaringan pemasaran dan jaringan pembiayaan akan dicari oleh Klibi serta perizinan sehingga para member akan bisa lebih maju lagi pada Masyarakat Ekonomi Asean (MEA) 2015, dikarenakan Negara luar akan melakukan Investasi yang bermuara kepada:

1. Makin banyak orang kaya di Indonesia yang menanamkan modal

2. Banyak pekerja professional yang handal

3. Turis akan lebih banyak sebagai gerbang masuk perdagangan domestic.

Perlunya dibuat persiapan Standard Nasional Indonesia (SNI) akan diminta walaupun masih perencanaan jangka panjang. Dalam kesempatan ini, diperlukan beberapa masukan dan informasi sebanyaknya, agar nantinya Klibi bisa menjadikan Klibi sebagai jembatan untuk pengembangan usaha dan yakinlah bahwa kesuksesan akan datang secara bertahap.

Dasar untuk meningkatkan kesejahteraan sosial melalui mentalitas dan budaya bisnis yang baik memiliki kemampuan untuk memberdayakan UMKM untuk meningkatkan kesejahteraan.Hal ini selajan dengan peateri berikutnya Bpk. Ahmad Rafiqi, B.BA, M.Mgt, Ph.D yang mengatakan bahwa untuk kegiatan di Negara-negara diperlukan untuk meningkatkan daya saing global. Barang yang diproduksi diperlukan suatu sertifikasi sehingga tidak bisa diclaim secara asalasalan. Di Malaysia, Kota Segamat, semua hasil olahan di Indoensia banyak diperjual belikan seperti Kain, Jamu, Roti Kacang. Jika Klibi mampu berdaya saing global, semua olahan dapat dijual di Malaysia dengan sertifikasi yang jelas dan dapat meningkatkan kesejahteraan bagi Indonesia sesuai dengan ide [4], [5], [6].

Perusahaan di Indonesia dalam menghadapi Masyarakat Ekonomi Asean (MEA) 2015 dan harus siap bersaing. Jadi kesiapan yang ada perlu dipersiapkan dan mengikuti Konsep UU World Trade Organization (WTO). Untuk melihat 
peluang dan tantangan, harus bersiap terhadap kemunculan kompetisi. Perlunya wadah di Kuala Lumpur yang antusias sebagai asosiasi bisnis di Negara lain seperti Malaysia dan Singapura. Perlu jua dilakukan analisis kasus dan berhati-hati terhadap informasi, fasilitas aktif pameran ke luar negeri seperti di Kuala Lumpur City Center (KLCC). Seiring dengan berkembangnya UMKM sebagai wirausaha mandiri, permintaan manusia selalu mengalami pertentangan dengan maraknya penawaran yang diberikan Klibi Tebing Tinggi harus memiliki strategi menuju bisnis Global seperti: strategi sumber daya, strategi menembus pasar, strategi perkembangan dan strategi bertahan. Namun kita wajib bersyukur bahwa Produk Indonesia banyak yang laris di penjualan dunia, seperti: Excelso, Paseo, Silver Queen, Polytron, JCO sesuai dengan pendapat [7].

Pengembangan diri melalui konsep sosial ekonomi, sangat lazim dipergunakan oleh semua pengambil keputusan untuk memetakan suatu kelompok masyarakat, Bpk Drs. Chairuddin Lubis memberikan materi tekad bisnis untuk kesejahteraan secara sosial ekonomi yaitu membuat bisnis dengan baik dan sejahtera diperlukan konsep bisnis, Bisnis itu adalah: mengelola, memimpin, mengurus dan melaksanakan. Bisnis global berat sehingga perlu dilakukan persiapan diri sehingga perlu diperhatikan:Nafsu, Akal yaitu adanya ilmu bisa gampang dengan ilmu dan kunci ibadah, Qalbu sesuai dengan pendapat [8].

Dengan semangat perubahan dan peran lembaga yang relevan, wajah lanskap lokal di suatu daerah dapat ditingkatkan kualitas sosial ekonomi Manajemen yang harus bangga dengan diri sendiri perlu melihat, mendengar dan dikelola semua. Yang ada di diri kita sehingga diperlukan persatuan untuk meningkatkan kemampuan bersama menuju keberhasilan. Keberhasilan merupakan suatu kebahagiaan. Bahagia merupakan konsep senang, tenang dan lapar. Ingatlah akan hokum dunia yang mengatakan jika ingin kaya, miskin dahulu dan jika ingin senang, susah dahulu. Jadilah kita menjadi sukses dengan Tekad, Berani, Rajin,. Kerjasama. Sebelum memasuki pembicara yang lain, dibuka sesi pertanyaan kepada audience untuk meningkatkan sisi interaktif seperti sejalan dengan ide [9]:

a. Usaha Jamur oleh Ibu Supraptie menanyakan bahwa Dinas Pemberdayaan Perempuan Kota Tebing Tinggi untuk menghimpun pelaku usaha wanita (IPPW) sebagai persatuan dan 21 April 2014 sudah dilantik dan akan dirinci tugas pokok dan fungsi pada setiap anggota. Bapak Wahyu Ario Pratomo menanggapi bahwa dengan adanya kegiatan IPPWU menyambut baik untuk bisa meningkatkan kesejahteraan keluarga, intinya bukan pisah dengan Klibi, namun bisa memperkuat Klibi lebih lanjut.

b. Siti Aniah dengan Usaha Kue Bawang Cabe Rawit menanyakan produksi untuk membuat kue bawang masih menggunakan produksi yang manual sedangkan permintaan pasar besar, bagaimana untuk mesin untuk bisa membantu proses usaha? Manajer Klibi menjawab bahwa tim Klibi Tebing Tinggi akan mencatat dan akan dikonfirmasikan kepada Cikal USU dan Inkubator untuk memberikan bantuan serta dicarikan Ahli untuk teknologi tepat guna.

Dengan meningkatnya perkembangan zaman, maka perkembangan teknologi, perlunya taste bisa dibuat untuk meningkatkan kemapuan untuk menyerap tenaga kerja. Dalam kesempatan ini, Pengusaha Gipang Kacang, Bapak Sakban menceritakan bahwa usaha beliau sudah memulai dengan teknologi 
dimana pelan-pelan untuk bisa masuk di internet, walaupun belum ada permintaan setidaknya produknya bisa dilihat masyarakat Indonesia.

Untuk pemateri Fahmi Natigor Nasution, SE, M. Acc, Ak memberikan motivasi dimulai dari tugas utama untuk Fakultas Ekonomi dan Bisnis Universitas Sumatera Utara adalah Pengajaran, Riset dan Penelitian serta Pengabdian Masyarakat. Kelayakan UMUM ialah hasil dari evaluasi proyek dengan menggunakan beberapa aspek yang akan menentukan apakah UMKM dapat berkembang sejalan dengan pemikiran [11].

Untuk mengembangkan jaringan (network) disatukan bagaimana untuk bisa semua member dapat berhasil, maka Fakultas Ekonomi dan Bisnis Universitas Sumatera Utara lebih berhasil lagi dan dapat berlangsung dengan baik. Konsep gagal dari bisnis, diperlukan oleh pebisnis untuk langsung terjun ke pasar. Agent yang tidak langsung ke lapangan, akan sulit berkembang dan harus diwarnai dengan baik untuk bisa berhasil. Bob Sadino, Chairul Tanjung selalu terjun, menikmati dan berdialog. Kalkulasi gampang untuk teknologi akan dibantu dan bisa dalam konteks produk. Ada stigma orang bisa berubah, saat ini jika kita pergi ke arab, oleh-olehnya bukan lagi kurma melainkan coklat dan bisa masuk ke konten lokal mereka.

Indonesia bisa menghasilkan segala-galanya. Apapun yang mau dibisniskan bisa dilakukan seperti Kelapa sawit, Gula aren. Yang penting perlu diperluas jaringan untuk meningkatkan kemakmuran bersama. Sebagqi contoh: pak Ahmad Rafiqi pemateri sebelumnya pernah rugi sampai dengan 200 juta, namun dikarenakan iklash dapt diganti dengan tamatnya gelar Ph.D dan terus mendapat rahmat dengan bisnis menjadi penulis di junal internasional yang rutin masuk di jurnal internasional bereputasi tinggi. Kesuksesan itu dilalui dengan tahapan kegagalan yang menjadi peningkatannya, bagaimana untuk mendewasakan diri dalam menerima kegagalan untuk bisa mendapat hasil yang lebih baik lagi sesuai dengan kebutuhan kita dan keiklashan akan membuat kita menjadi insan mulia.

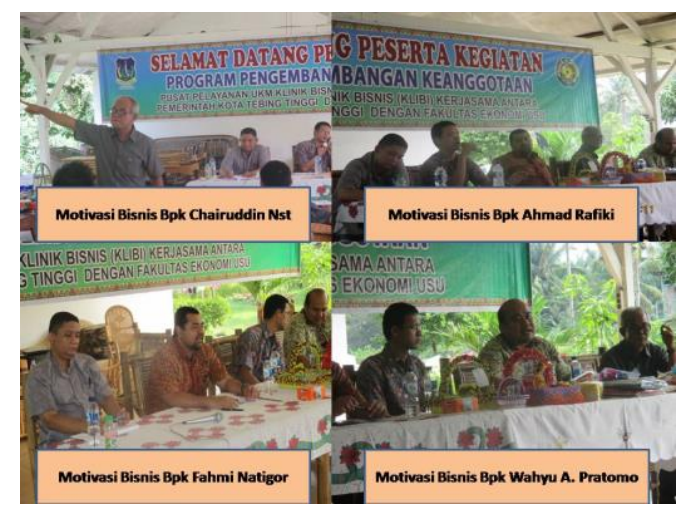

Gambar 1. Inspirasi Bisnis Terindah Dewan Pakar FEB USU Tahun 2015

Untuk perbankan, Klibi Tebing Tinggi bekerjasama dengan Bank Syariah Mandiri Cab. Lubuk Pakam yang diwakili oleh Bpk. Dodi Rahman Nasution yang menjelaskan mengenai produk pembiayaan mikro. Dalam materinya, beliau menyampaikan bahwa landasan hukum Bank Syariah sudah terdapat di setiap produknya. Untuk pembiayaan Bank Syariah memiliki jenis yaitu:

1. Pembiayaan mikro tunas dimulai dari pinjaman 2 juta s.d 10 juta 
2. Pembiyaan mikro madya dimulai dari 10 juta s.d 50 juta

3. Pembiayaan mikro utama dimulai dari 50 juta s.d 100 juta

Secara umum Bank Syariah merupakan bank yang berlandaskan syariah sehingga menganut sistem bagi hasil bagi para penabung dengan usaha syariah islam sehingga usaha yang disalurkan sesuai dengan syariah yang ditentukan di awal. Untuk Bank Konvensional, terjadi konsep bunga dan keuntungan dari penabung adalah tetap (fixed). Plat Form 2 juta s.d 10 juta sesuai dengan kebutuhan dan khusus untuk bahan baku dapat dipertanggung jawabkan sesuai dengan kriteria peminjam yang tertuang dalam konsep peminjaman.

Untuk program kredit tanpa agunan (KTA) merupakan konsep yang dihapuskan dikarenakan adanya moral obligation misalnya $40 \%$ dari pendapatan suami dan istri sehingga $60 \%$ digunakan untuk pembayaran. Untuk UMK Klibi Tebing Tinggi diharapkan untuk membuat pembukuan yang baik. Perbankan bukanlah lembaga yang hanya khusus melalang saja namun tetap terbina simbiosis mutualisme. Untuk Bank Syariah Mandiri juga memiliki target masing-masing bagi setiap marketing sehingga performance yang meminjam uang dapat dievaluasi secara rutin.

Untuk pemateri berikutnya disampaikan oleh Bpk Hadi Wibowo selaku owner lima warna dan juga market research di Perusahaan GIGA. GIGA sudah memiliki tim yang solid dan mempunyai landasan bisnis plan yang jelas. GIGA berupaya untuk membantuk mitra UMK Klibi Tebing Tinggi dalam pemasaran produknya sehingga jika produk sudah layak untuk dipasarkan, tidak akan mendapat pertanyaan dari para investor. Untuk saat ini, perusahaan besar yang ingin melangkah lebih cepat, bisa melakukan invasi dan banyak hal yang bisa dijual yaitu untuk mendapatkan mitra kerja seperti: membuat Bisnis Plan, membeli Standard Operation Procedure, melakukan Promotion.

Tim GIGA akan melakukan seleksi berbagai produk UMK Klibi Tebing Tinggi untuk bisa dipasarkan di beberapa propinsi dan perlu dilakukan standarisasi yang jelas dari produk hasil olahan tersebut. Untuk tahap penyeleksian, dilakukan di akhir acara dan dibantu oleh tim kreatif dari GIGA. Sebelum mengakhiri sesinya. Bapak Hadi Wibowo mendapatkan pertanyaan dari audience yaitu dari Ibu Sri Yayuk yaitu untuk orderan dari produk tas dari bisnis yang digeluti, terkendala oleh bahan baku secara terus menerus, ibu tersebut menanyakan solusinya.Untuk menjawab pertanyaan tersebut, pemateri menjawab bahwa adanya brand di Singapura sangat top dan dapat terlihat di Sumatera Utara dan diperlukan bisnis secara patungan untuk menghimpun brand yang terbaik. Hal lain yang dapat dilakukan adalah mencoba mencari alternative dengan komunitas bisnis yang berada di Kota Medan untuk bisa menghimpun berbagai relasi dari bahan yang ingin dicari. Hal ini memang dibutuhkan suatu fleksibilitas dari para UMKM untuk membina jaringan dimana pun juga. Di akhir acara, moderator dari EDP memberikan inspirasi mengenai konsep bisnis yang kreatif dan inovatif lebih dikembangkan dan sudah bisa memulai dengan menggunakan bisnis online dikarenakan perkembangan ekonomi yang sangat pesat, membuat banyak perusahaan baik yang bergerak dibidang jasa maupun produksi serta perdagangan berlomba-lomba untuk memperoleh keuntungan yang lebih baik guna keberlangsungan usahanya melalui toko online karena 1. Leluasa dimana UMKM 
lebih leluasa untuk mengatur dan mengelola toko online. Kendali sepenuhnya di tangan anda, 2. Bebas Resiko, dngan memiliki Toko Online sendiri, Anda bebas dari resiko akun yang disuspen (Tutup), 3. Pandangan Jauh ke depan. Untuk branding dan marketing, potensi toko online milik UMKM menjadi besar di masa depan Intinya. Jika toko online semakin ramai dan tenar, maka kesempatan bagi UMK Klibi Tebing Tinggi untuk mengelola konsumen dan para pembeli pun menjadi semakin mudah dengan kendali berada di tangan Klibi. Hubungan yang bisa dibina untuk kedepan adalah: Reseller, Dropshipper, Pemasang Iklan, pemasok barang dan sebagainya untuk lintas propinsi di Indonesia bahkan negara-negara internasional. Semua inspirasi bisnis dapat memberikan semangat bagi para member untuk sukses berkompetisi dalam menjalani MEA sejalan dengan pemikiran [11].

\section{KESIMPULAN}

Dari hasil dan pembahasan yang sudah dilakukan, dapat ditarik kesimpulan yaitu:

a. Perkembangan Kota Tebing Tinggi yang akan dilintasi pembangunan jalan tol, Klibi berharap untuk bisa menyewa beberapa tempat didekat jembatan Tol untuk bisa nantinya dijual segala sesuatu hasil olahan yang terbaik.

b. Masyarakat Ekonomi Asean (MEA) 2015, dikarenakan Negara luar akan melakukan Investasi yang bermuara kepada:Makin banyak orang kaya di Indonesia yang menanamkan modal, Banyak pekerja professional yang handal, Turis akan lebih banyak sebagai gerbang masuk perdagangan domestik.

c. UMKM sebagai wirausaha mandiri, permintaan manusia selalu mengalami pertentangan dengan maraknya penawaran yang diberikan Klibi Tebing Tinggi harus memiliki strategi menuju bisnis global seperti: strategi sumber daya, strategi menembus pasar, strategi perkembangan dan strategi bertahan

d. Untuk mengembangkan jaringan (network) disatukan bagaimana untuk bisa semua member dapat berhasil, maka Fakultas Ekonomi dan Bisnis Universitas Sumatera Utara lebih berhasil lagi dan dapat berlangsung dengan baik. Konsep gagal dari bisnis, diperlukan oleh pebisnis untuk langsung terjun ke pasar.

e. UMKM Klibi Tebing Tinggi mencoba mencari alternative dengan komunitas bisnis yang berada di Kota Medan untuk bisa menghimpun berbagai relasi dari bahan yang ingin dicari. Hal ini memang dibutuhkan suatu fleksibilitas dari para UMKM untuk membina jaringan dimana pun juga.

f. UMKM binaan Klibi Tebing Tinggi wajib mengembangkan toko online karena 1. Leluasa dimana pun lebih leluasa untuk mengatur dan mengelola toko online, Kendali sepenuhnya di tangan anda, 2. Bebas Resiko, dngan memiliki Toko Online sendiri, Anda bebas dari resiko akun yang disuspend (Tutup), 3. Pandangan Jauh ke depan. Untuk branding dan marketing.

\section{UCAPAN TERIMA KASIH}

Penelitian ini merupakan bagian dari luaran prosiding nasional yang dibiayai oleh Direktorat Riset dan Pengabdian Masyarakat Direktorat Jendral Penguatan Riset dan Pengembangan Kementrian Riset, Teknologi dan Pendidikan Tinggi Tahun 2018 sesuai dengan Kontrak Penelitian Nomor : T/44/L1.3.1/PT.01.03/2019 


\section{DAFTAR PUSTAKA}

[1] Ami, Dilham and Putra, M. Umar Maya., "Socio economic community mapping around Dumai Timur (case study: Tanjung Palas Village)," in IOP Conf. Series: Earth and Environmental Science 126 (2018) 012085, 2017, pp. 1-10.

[2] Bati, Putra, M. Umar Maya and H. Sahla., "Focus Group Discussion For Young Entrepreneurs Training in University Of Asahan, in 2nd Annual International Seminar on Transformative Education and Educational Leadership (AISTEEL 2018)" vol. 200, pp. 1-4, 2018.

[3] M. S. Malawat and Putra, M. Umar Maya., "Review Of Implementation In Bunut Shoes Assistance Program In Order Of Micro, Small And Medium Enterprises Economic In Asahan Regency," in Journal of Physics: Conference Series, 2018, vol. 970, no. 1, pp. 1-6.

[4] S. Malawat and Putra, M. Umar Maya., "Socio Economic Kisaran Barat Community Mapping In Asahan Regency," pp. 706-713, 2018.

[5] Saleh, Malawat and Putra, M. Umar Maya., "Business start-up empowerment in asahan district 1," in The 1st Multi-Discipinary International conference University Of Asahan2019 Thema: The Role of Science in Development in the Era of Industrial Revolusion 4.0 based on Local Wisdom." in Sabty Garden Hotel-Kisaran North Sumatra, March 23rd, 2019 Business, 2019, pp. 299-304.

[6] Putra, M. Umar Maya and Ami, Dilham., "An Effectiveness Analysis of Corporate Social Responsibility of Empowerment Program in Terminal BBM Pertamina Siantar," 2017, no. 1987, pp. 457-463.

[7] Syarifah, Tengku and Putra, M. Umar Maya., "Motivation And Entrepreneurs Training For Tinggi Raja Society of Asahan Regency," in 2nd Annual International Seminar on Transformative Education and Educational Leadership (AISTEEL 2017) Motivation, 2017, vol. 104, no. Aisteel, pp. 1-5.

[8] Putra, M. Umar Maya and Ami, Dilham., "Pemetaan Sosial Ekonomi Masyarakat Kecamatan Medan Labuhan Kota Medan," in Seminar Nasional Teknologi Informatika, "The Future of Computer Vision", 2017, ISBN : 978-602-50006-0-7, 2017, pp. 8-15.

[9] A. Dilham and Putra, M. Umar Maya., "Social Economic Community Mapping Around Binjai Utara ( Case Study: The People In Tandem Hilir )," in Proceedings of the 1st Annual International Seminar on Transformative Education and Educational Leadership (AISTEEL 2016) e-ISSN: 2548-4613, 2016, no. Ii, pp. 600-607.

[10] Delvi and Putra, M. Umar Maya., "Kajian Studi Kelayakan,” Hum. FALAH, vol. 4, no. 1, pp. 87104, 2017.

[11] Putra, M. Umar Maya and A. Dilham., "Pemetaan Sosial Ekonomi Kecamatan Dumai Timur ( Studi Kasus : Kelurahan Bukit Timah ),” vol. 7, no. April, pp. 1-8, 2017. 